\title{
PENYULUHAN PEMILAHAN DAN PENGELOLAAN SAMPAH DI DESA SIDAKARYA, DENPASAR SELATAN
}

\author{
Luh Ayu Rianawati Pradnya Paramitha ${ }^{1}$, Komang Sri Widiantari ${ }^{2}$ \\ 1Program Studi Manajemen, Universitas Pendidikan Nasional \\ 2Program Studi Akuntansi, Universitas Pendidikan Nasional \\ Email: ${ }^{1 L a r p p a r a m i t h a @ g m a i l . c o m, ~}{ }^{2}$ Widiantari@undiknas.ac.id
}

\begin{abstract}
Abstrak
Bali merupakan pulau yang terkenal dengan kekayaan alam, adat-istiadat, dan juga budaya yang dimiliki, maka dari itu Bali disebut sebagai pulau pariwisata. Pulau Bali terdiri dari 8 kabupaten, 1 kotamadya yaitu Kota Denpasar. Di Desa Sidakarya, Denpasar Selatan, ini merupakan lokasi dari kegiatan kuliah kerja nyata (KKN) terlaksana. Permasalahan yang terjadi di Desa Sidakarya ini adalah kurang pedulinya masyarakat terhadap pemilahan dan pengelolaan sampah. Maka dari itu denga $n$ adanya kuliah kerja nyata ini, untuk lebih masyarakat menjalankan prinsip 3R (Reduce, Reuse, Recycle). Kuliah kerja nyata (KKN) dapat membantu memberikan solusi permasalahan dengan menggunakan metode penyuluhan yang berupa video lalu di sebarkan kepada masyarakat, alasan penggunaan video ini untuk lebih memudahkan masyarakat mengakses informasi pada masa pandemic Covid-19, sedangkan kegunaan poster yang di pasang sekitar wilayah Sidakarya untuk lebih mengingatkan tentang bahaya sampah. Hasil akhir dari pengabdian ini dengan melakukan penyuluhan online dengan menggunakan video yang di sebarkan di Youtube dan juga pemasangan spanduk di titik tertentu. Rencana keberlanjutan dari kegiatan ini adalah pengoptimaliasian dari pembuatan Platform seperti Instagram yang didalamnya berisikan konten-konten pemilahan dan pengelolaan sampah. Selain itu adanya bantuan tempat sampah dari Desa Sidakarya untuk pemilahan sampah organik dan anorganik. Hal ini dapat membantu meningkatkan kesadaran masyarakat dan membantu meringankan tugas dari petugas kebersihan.
\end{abstract}

Kata Kunci: Pemilahan, Pengelolaan, Sampah, dan 3R

Bali is an island that is famous for its natural wealth, customs, and culture, therefore Bali is known as the island of tourism. The island of Bali consists of 8 districts, 1 municipality, namely Denpasar City. In Sidakarya Village, South Denpasar, this is the location where the real work class (KKN) activity takes place. The problem that occurs in Sidakarya Village is the community's lack of concern for sorting and managing waste. According to Taqim (2007) said that in practice replant (replanting) is not the choice of the majority of the community so that the principle becomes 3R (Reduce, Reuse, Recycle). Therefore, in this real work lecture (KKN) can help provide solutions to problems by using the counseling method in the form of a video and then distributed to the community, after doing this there is a banner installation around the Sidarkarya Village area. The end result of this service is by conducting online counseling using videos that are distributed on Youtube and also installing banners at certain points. The plan for the sustainability of this activity is to optimize the creation of a platform like Instagram, which contains waste sorting and management content. In addition, there is assistance from trash cans from Sidakarya Village for sorting organic and inorganic waste. This can help raise public awareness and help ease the duties of the janitor.

Keywords: Sorting, Management, Waste, and $3 R$ 


\section{PENDAHULUAN}

Pulau Bali terdiri dari 8 kabupaten, 1 kotamadya yaitu Kota Denpasar yang memiliki jumlah penduduk sebanyak 962.900, tepatnya di Denpasar Selatan memiliki jumlah penduduk sebanyak 311.590 jiwa (BPS Kota Denpasar,2020). Dengan jumlah penduduk tersebut hampir semua aktivitasnya meninggalkan bekas atau sisa kegiatan yang berupa sampah. Bermula dari kegiatan rumah tangga seperti memasak, perbaikan rumah, penggunaan produk-produk seperti produk mandi, makan dan lain sebagainya. Adanya penumpukan dan membuang sembarangan ke kawasan terbuka akan mengakibatkan pencemaran tanah yang juga akan berdampak ke saluran air. Pembakaran sampah akan mengakibatkan pencemaran udara, pembuangan sampah ke sungai akan mengakibatkan pencemaran air, tersumbatnya saluran air pada akhirnya menyebabkan banjir.

Dengan adanya kesadaran masyarakat akan sampah sangat penting untuk kelestarian lingkungan dan hidup manusia sendiri. Mengenai masalah tersebut menurut dari (Sucipto, 2012) masalah sampah merupakan fenomena sosial yang perlu mendapat perhatian khusus dari semua pihak, karena setiap manusia pasti memproduksi sampah. Besarnya timbunan sampah yang tidak dapat ditangani tersebut akan menyebabkan berbagai permasalahan yang timbul akibat kurangnya alternatif dan perspektif masyarakat terhadap pengelolaan dan pemanfaatan sampah, baik langsung maupun tidak langsung. Masalah sampah di Kota Denpasar sudah sering menjadi bahan keluhan masyarakat dan wisatawan karena banyak terdapat sampah di tempat-tempat pariwisata hingga lingkungan sekitarnya. Perspektif mengenai pengelolaan sampah dan pemilahan sampah dengan relevansi etika lingkungan didalamnya serta menggunakan paham analisis dampak lingkungan. Pemerintah Kota Denpasar, telah menyadari kondisi tersebut untuk itu, perlu adanya perubahan pola penanganan sampah. Hal itu membuat aparatur pemerintah berwenang dan berkewajiban menegakkan hukum dalam arti mengusahakan agar setiap norma yang ditetapkan hukum lingkungan ditaati oleh masyarakat. Desa Sidakarya salah satu desa di kota Denpasar yang secara geografis terletak di muara sungai sehingga sangat mungkin terjadinya penumpukan sampah di musim penghujan. Sumber sampah bermula dari pusat perbelanjaan, toko modern, pasar tradisional, dan rumah tangga. Penumpukan terjadi dikarenakan kurangnya kesadaran masyarakat untuk peduli dalam pemilahan sampah dan pengelolaan sampah.

Dari penelitian terbaru menurut dari (muhajir, 2019) mengatakan setiap harinya Bali menghasilkan sampah sebanyak 4.281ton atau 1,5 juta ton tiap tahunnya dengan persentase 52\% tidak dikelola dan 48\% terkelola. 50\% sampah di bali berasal dari daerah padat aktivitas yang berlangsung seperti Denpasar, Badung, dan Gianyar yang pada akhirnya akan dibawa ke TPA sebanyak 70\% . Penting adanya pengelolaan sampah menggunakan prinsip $4 \mathrm{R}$ (reduce, reuse, recycle, replant) yang menjadi tren yang telah dijalankan oleh masyarakat. Menurut dari (taqim, 2007) mengatakan dalam praktiknya replant (menanam kembali) bukan menjadi pilihan mayoritas masyarakat sehingga prinsip tersebut menjadi 3R (reduce, reuse, recycle).

Dalam Kuliah Kerja Nyata kali ini, saya memilih Desa Sidakarya karena merupakan desa yang terletak di Kecamatan Denpasar Selatan, Kabupaten Denpasar yang mayoritas masyarakatnya merupakan pendatang dan beberapa penduduk asli sini. Dikarenakan permasalahan yang di ambil dalam kasus kurangnya pemilahan dan pengelolaan sampah oleh masyarakat ini menjadi sumber yang perlu di optimalisaikan untuk Desa Sidakarya, Denpasar Selatan, Bali. Dampak yang terjadi di dalam masyarakat yang kurang peduli terhadap pemilahaan dan pengelolaan sampah. Tujuan dari adanya kuliah kerja nyata (KKN) yaitu untuk mengetahui penyebab terjadinya kurang peduli msyarakat terhadap pemilhan dan pengelolaan sampah. Serta membantu memberikan strategi dan solusi atas permasalahan yang ada agar kedepannya lebih 
baik dan efektif.

Walaupun sudah ada kebijakan-kebijakan pengelolaan sampah di Kota Denpasar tetapi kenyataannya masih terjadi penumpukan sampah di TPS dan TPA dimana kondisinya masih terjadi pencampuran sampah organic dan anorganik (plastic), khusus diseputaran Desa Sidakarya. Kurang sadarnya masyarakat tererhadap pemilahaan dan pengelolaan sampah ini membuat TPS kewalahan dan hal ini terjadinya penumpukan sampah. Untuk itu adanya penerapan $3 \mathrm{R}$ di dalam pengelolaan sampah di tingkat masyarakat. Solusi dari kegiatan ini dalam menerapkan pengoptimalisaian pemilahaan dan pengelolaan sampah oleh masyarakat di Desa Sidakarya, Denpasar Selatan, Bali adalah dengan menggunakan cara penyuluhan kepada masyarakat dengan menggunakan video yang disebarkan melalui sosial media atau spanduk yang bertema mengajak masyarakat untuk memilah sampah yang ada pada titik-titik tertentu.

\section{METODE}

Dalam menjawab permasalahan rumusan masalah serta memecahkan permasalahan dan melakukan penerapaannya dengan melakukan beberapa metode. Dengan metode penyuluhan online yang berupa sebuah video yang di sebarkan dan di dialam isi video itu menjelaskan tentang Metode SOS (sort out, saved) ini merupakan metode yang dapat mempemudah dalam mengingat adanya konsep 3R (reduce, reuse, recycle). Video ini telah dikirimkan pada Pejabat Perbekel Desa Sidakarya dan dibagikan ke grup beberapa staf dan pengurus masing-masing Banjar yang berisi 15 anggota. Konsep 3R ini yaitu adanya pemilahan sampah, lalu dikumpulkan dan diharapakan dapat menciptakan lingkungan bebas sampah dan sampah tidak akan menjadi masalah yang krusial di masing-masing lingkungan tersebut.

Menurut dari Manik, (2004: 67) dapat di bagi jenis sampah berdasarkan zat pembentuknya menjadi 2 yaitu sampah organik dan sampah anorganik:

1. Sampah organik merupakan sampah dari bahan penyusun hewan dan juga tumbuhan. Selain itu komponen lainnya seperti makanan dan kertas.

2. Sampah anorganik merupakan sampah dari sumber daya alam yang tidak terbaharui di golongkan dalam sampah anorganik seperti mineral, proses industry, dan eksplorasi minyak. Dimana sampah ini secara umum tidak dapat diuraikan atau sulit diuraikan secara alami.

Kegiatan penyuluhan metode pembuangan sampah organik dan anorganik rumah tangga di Desa Sidakarya, Denpasar Selatan ini akan dilaksanakan dengan berbagai kegiatan, sebagai berikut:

1. Survei Lapangan Survei lapangan di Desa Sidakarya, bertujuan untuk mengamati situasi dan keadaan masyarakat yang direncakan sebagai objek sasaran.

2. Koordinasi dengan pihak Kepala Desa Sidakrya untuk menentukan melakukan penyuluhan dengan mengedarkan video penyuluhan terkait pemilahan dan pengelolaan sampah.

3. Pelaksanaan Penyuluhan yang berupa video:

a) Menjelaskan serta memaparkan materi kajian sampah,

b) Menjelaskan jenis sampah yaitu organik dan anorganik, dan sumber sampah, pentingnya pembuangan sampah sesuai dengan jenisnya dan dampak pembuangan sampah sembarangan baik itu bagi lingkungan maupun bagi kesehatan. Serta Simulasi/demonstrasi yaitu pemberian Spanduk di titik tertentu.

4. Evaluasi Kegiatan Mengevaluasi perkembangan dari pelaksanaan penyuluhan tentang pemilahan dan pengelolaan pembuangan sampah organik dan anorganik di Desa Sidakarya, Denpasar Selatan. 
5. Indikator Keberhasilan Indikator keberhasilan yang menjadi acuan dalam pelaksanaan penyuluhan dan simulasi ini adalah:

a. Masyarakat Desa Sidakarya dapat melaksanakan pemilahan dan pengelolaan sampah.

b. Dapat tercipta lingkungan yang bersih dan sehat karena dengan pengelolaan sampah organik dan anorganik yang baik.

Menurut dari Apriadji bahwa pembuangan sampah terangkai dari 3 kegiatan sebagai berikut:

1. Penampungan sampah (refuse storage)

2. Pengumpulan sampah (refuse collection)

3. Pembuangan sampah (refuse disposal)

Dengan demikian penjelasan yang ada di atas tentang pemilahan sampah bisa diartikan suatu proses kegiatan penanganan sampah sejak dari sumbernya. Dengan itu memanfaatkan penggunaan sumber daya secara efektif yang diawali dari adanya pewadahan, pengangkutan, pengumpulanan, pengolahan, hingga pembuangan, melalui pengendalian pengelolaan organisasi yang berwawasan lingkungan, sehingga dapat mencapai tujuan untuk terciptanya lingkungan bebas sampah.

\section{HASIL DAN PEMBAHASAN}

Permasalahan yang di alami oleh Desa Sidakarya, Denpasar Selatan yaitu kurang pedulinya masyarakat terhadap pemilahan dan pengelolaan sampah. Hal itu membuat petugas kebersihan kewalahan dan TPS jadi menumpuk. Dalam permasalahn tersebut adanya solusi dengan melakukan penyuluhan yang sekarang bisa di lakukan dengan membuat video penyuluhan dan di bagikan kepada masyarakat. Video yang dibagikan tersebut berisikan tentang apa itu sampah, komposisi sampah, dampak negative, cara pemilhan sampah, penjelaan 3R (Reduce, Reuse, Recycle), cara pengelolaan sampah, dan mengajak masyarakat untuk memilah dan mengelola sampah mulai dari lingkungan sekitar. Oleh sebab itu, pengabdian ini dilakukan untuk memberikan penyuluhan untuk memecahkan masalah yang berkaitan dengan strategi penerapan kepada masyarakt untuk memilah dan mengelola sampah dengan baik dan benar.

Pengabdian yang dilakukan di Desa Sidakarya, Denpasar Selatan ini dimulai dari turun langsung untuk melakukan peninjauan kelapangan, bahwa sampah yang ada pada TPS membuat petugas kebersihan kewalahan dan memilah sampah-sampah. Untuk itu terdapat beberapa hal yang diperlukan oleh masyarakat agar memperbaiki kondisi yang ada sebagai berikut:

1. Adanya Penyuluhan atau Sosialisasi yang menggunakan video sebagai alat untuk terjadinya penyuluhan. Adanya Kesadaran akan pentingnya menjaga kebersihan lingkungan serta mengingatkan masyarakat untuk membuang sampah pada tempatnya sehingga diharapkan masyarakat dapat menjaga kebersihan lingkungan dan merubah kebiasaan mereka.

2. Tempat Sampah menjadi salah satu media yang membuat masyarakat membuang sampah pada tempatnya dan dari hal ini masyarakat dapat belajar untuk membuang sampah terhadap jenisjenisnya.

3. Pengelolaan Sampah yang di lakukan secara Mandiri merupakan salah satu tujuan untuk meningkatkan kepedulian masyarakat akan lingkungan sekitar. Dalam hal ini pengelolaan sampah perlu dilakukan secara mandiri agar seluruh masyarakat Desa Sidakarya turut bekerjasama untuk menjaga lingkungan.

4. Selain itu adanya Petugas Kebersihan berfungsi untuk mengambil sampah-sampah yang ada di tempat sampah secara rutin sehingga tidak terjadi penumpukan sampah di wilayah sekitar. Adanya penyuluhan dan pembuatan spanduk yang di pasang di titik tertentu untuk membuat masyarakat lebih sadar dan hal ini dapat membantu meringankan petugas kebersihan. Dalam memecahkan masalah yang ada di Desa 
Sidakarya, Denpasar Selatan menggunakan video penyuluhan yang di sebarkan kepada masyarakat dan juga pemasangan spanduk di sekitar wilayah Desa Sidakarya seperti gambar berikut:
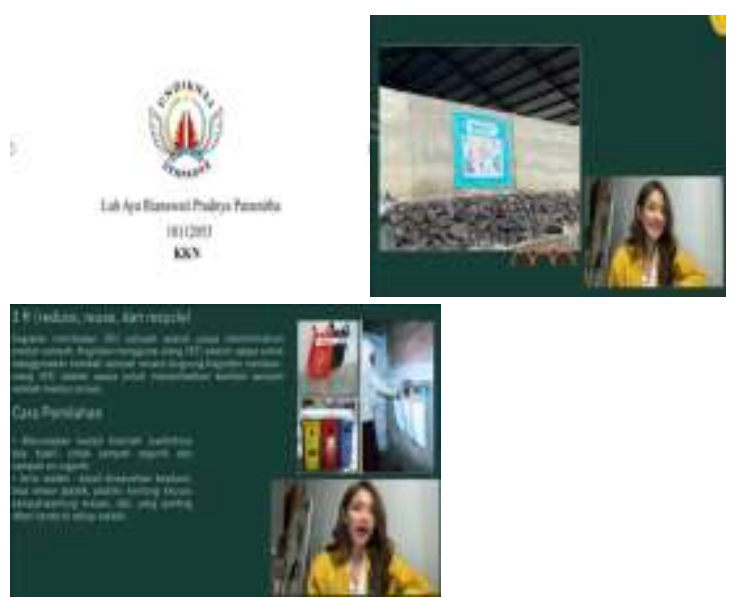

Gambar 3.1 Video Penyuluhan Pemilahan dan Pengelolaan Sampah

Dari video penyuluhan pemilahan dan Pengelolaan Sampah yang di edarkan kepada masyarakat di Desa Sidakarya, Denpasar selatan ini, menggunakan Social Media berupa Platform yaitu Youtube ini adalah linknya: https://youtu.be/4ZqWbmT4Ftg

Selain dari video penyuluhan yang di berikan kepada masyarakat di Desa Sidakarya dalan kuliah kerja nyata (KKN) ini juga memberikan beberapa spanduk yang di pasang di sekitar wilayah Desa Sidakarya seperti berikut:

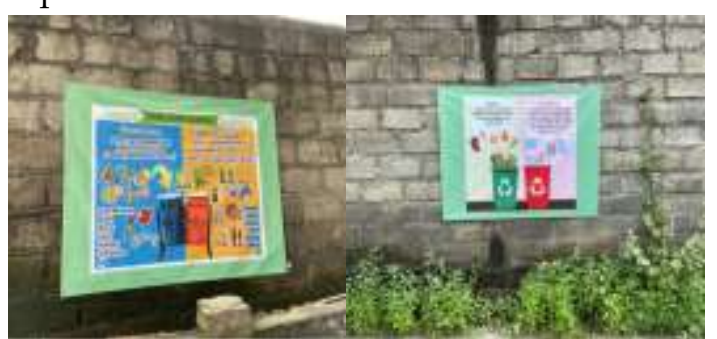

Gambar 3.2 Pemasangan Spanduk di daerah Sidakarya

Dalam kegiatan kuliah kerja nyata ini dalam pemillahan dan pengelolaan sampah di Desa Sidakarya, warga belum menyadari bahwa hal tersebut sangat berpengaruh pada masalah yang lingkupnya lebih luas yaitu kelestarian lingkungan hidup di sekitarnya. Karena itu petugas kebersihan kesusahan dan pekerjaannya menjadi terhambat dalam pemilahaan sampah. Dari permasalahan tersebut adanya foto Before sebelum terjadinya penyuluhan melalui video yang di bagikan kepada masyarakat Desa Sidakarya.

Hasil dari pelakasaan kuliah kerja nyata di Desa Sidakarya ini yang berupa penyebaran video dan pemasangan spanduk di sekitar wilayah Desa Sidakarya mendapatkan respon positif. Hal ini dapat mengurangi pekerjaaan petugas kebersihan setempat. Setelah penyuluhan tentang pemilahan dan pengelolaan sampah mandiri, masyarakat sekitar dapat memahami cara pemilahan sampah yang sebelumnya sangat minim menjadi meningkat, dari hanya sedikit warga yang mengetahui menjadi banyak warga yang mengetahui. Dengan hal itu mendapatkan hasil yang baik dari masyarakat dan dapat membantu sedikit mengurangi petugas kebersihan yang ada di Desa Sidarya.

Desa Sidakarya merupakan tempat pelaksanaan Kuliah Kerja Nyata, dimana KKN ini merupakan salah satu syarat kelulusan sebagai mahasiswa UNDIKNAS. Permasalahan yang ada di desa ini tentang kurang pedulinya masyarakat terhadap pemilahan dan oengelolaan sampah mandiri. Hal ini berdampak kepada lingkungan sekitar dan juga kewalahan bagi petugas kebersihan dalam memilah sampah. Dari hasil penyuluhan dan pemasangan spanduk di wilayah sekitar meningkatnya kepedulian masyarakat atas pemilahaan dan pengelolaan sampah. Dengan itu pelaksanaan strategi yang di lakukan berjalan sesuai dengan harapan dan dapat diterima dengan baik oleh lapisan masyarakat yang terlibat.

\section{KESIMPULAN DAN SARAN}

Kesimpulan

Pada kegiatan kuliah kerja nyata $(\mathrm{KKN})$ ini membantu Desa Sidakarya dalam menyelesaikan permasalahan tentang kurang pedulinya masayarakat terhadap pemilahan dan pengelolaan sampah di lingkungan sekitar. Dalam permasalahan ini mempengaruhi keterlambatan dan kewalahannya para petuga kebersihan setempat dalam memilah sampah. Karena hal tersebut membuat sampah menumpuk pada TPS Desa Sidakarya. Dengan melalukan penyuluhan secara online 
menggunakan video yang di sebarkan melalui Youtube ini dapat menjadi bekal pembalajaran untuk masyarakat dalam memilah dan mengelola sampah mandiri dengan baik dan benar. Selain itu adanya pemasangan spanduk di wilayah sekitar dapat menjadi efisien dalam melakukan tindakan peduli lingkungan sekitar. Hasil dari penelitian ini dapat di terima dengan baik oleh masyarakat sekitar dengan itu dapat membantu menyelesaikan permasalahn di Desa Sidakarya, Denpasar Selatan.

Saran

Saran yang dapat di berikan kepada agar terus mengikuti pemilahan dan pengelolaan sampah. Keberlanjutan dari kegiatan pengabdian kepada masyarakat ini adalah mengeoptimalkan pembuatan platform lain seperti Instagram. Dalam melakukan pengoptimalan pengembangan Instagram untuk Desa Sidakarya, Denpasar Selatan dapat membahas seperti pembahasan tentang

\section{DAFTAR PUSTAKA}

Dian Fordian, H. A. (2017). Penyuluhan Metode Pembuangan Sampah Organik dan Sampah Non Organik Bagi Rumah Tangga Di Lingkungan (Studi Kasus Rw 03 Desa Cisempur, Kec. Jatinangor). Jurnal Aplikasi Ipteks untuk Masyarakat, : 129 - 135.

I Wayan Arthanaya, I. G. (2020). PKM Banjar Sari Desa Sidakarya Denpasar Selatan. Community Services Journal (CSJ).

Kristina, I. G. (2021). Pengelolaan Timbunan Sampah untuk menjaga Citra Industri Pariwisata pada daya tarik Wisata di Bali. Pusaka, Vol 3 No 1.

Kristina, I. G. (2021). Pengelolaan Timbunan Sampah untuk menjaga Citra Industri Pariwisata pada daya tarik Wisata di Bali. Pusaka, Vol 3 No 1.

Nandari, I. N. (2020). Pemberdayaan Masyarakat Dalam Pengelolaan pemilahan dan pengelolaa sampah dengan baik dan benar. Selain dari pengoptimalan pada Instagram, adanya bantuan tong sampah untuk memilah sampah organic dan anorganik dari desa kepada masyarakat wilayah sekitar. Hal itu dapat membantu masyarakat untul lebih bisa meningkatkan pemilahaan sampah mandiri dengan baik dan benar serta dapat berjangka Panjang untuk kedepannya.

Diharapkan dalam pelakasanaan kuliah kerja nyata (KKN) ini terjadi peningkatan kesadaran masyarakat terhadap sampah. Kegiatan ini tentunya menjadi hal yang sangat penting untuk menjaga kelesatarian alam sekitar terutama di Desa Sidakarya, Maka dari itu dalam pengotimalisaian pemilahan dan pengelolaan sampah dapat berjalan dengan baik sesuai dengan tujuan dari pelaksaan kuliah kerja nyata (KKN) yang dapat membantu Desa Sidakarya, Denpasar Selatan, Bali.

Sampah Rumah Tangga melalui Bank Sampah di Desa Sidakarya Denpasar Selatan. Parta: Jurnal Pengabdian Kepada Masyarakat, Vol 1 , no 1.

Ni Putu Amelia Panida Dewi, I. A. (2021). Efektivitas Sistem Pengelolaan Sampah Berbasis Masyarakat (Studi Kasus: Desa Sanur Kaja Kota Denpasar). Inpress, Vol 9 No 2.

Proyeksi penduduk Bali. (2020). From Badan pusat statistik Bali: https://bali.bps.go.id/

Proyeksi Penduduk Kota Denpasar (Jiwa), 2018-2020. (2020). From Badan pusat statistik Kota Denpasar: https://denpasarkota.bps.go.id/in dicator/12/49/1/proyeksipenduduk-kota-denpasar.html

Sang Kompyang Putra Prawira, N. K. (2021). Perancangan Video Iklan Layanan Masyarakat dan Media Pendukung sebagai Sarana Sosialisasi Pengolahan Sampah Berbasis Sumber di Desa Temesi. Amarasi, Vol 2 No 1.

Setyawan, P. E. (2016). Penyuluhan Tentang Pengelolaan Sampah Dan 
Pembuatan Tempat Sampah Unik DariI Pipa PVC Untuk Masyarakat Desa Srigading Kecamatan Lawang. Jurnal ABDIMAS Unmer Malang, Vol. 1, Nomor 2.

Tutesa, Y. W. (2020). Meningkatkan
Kepedulian terhadap Kelestarian Lingkungan Hidup Melalui Pemilahan Sampah Mandiri. Jurnal Pendidikan Ilmu Pengetahuan Sosial , Vol. 12 No.2. 